\title{
Editorial
}

\section{Dossiê Circulação de Ideias e Imagens}

A circulação e a difusão espacial de imagens, textos, corpos e ideias são parte relevante nas investigações engajadas em abordagens culturais na geografia humana. Desde Ratzel, o estudo da circulação dos elementos culturais e sua assimilação em diferentes espaços aparece como um elemento de interesse dos geógrafos. As visitas de Ratzel aos Estado Unidos em 1873 e 1875 deram estímulo a seus trabalhos sobre a migração chinesa no mundo, nos quais investigava como artefatos materiais e práticas culturais circularam em conjunto à circulação das pessoas. Contrastando com visões estereotipadas e pouco criteriosas sobre o autor alemão, geógrafos contemporâneos têm afirmado que "talvez o maior mérito de Ratzel tenha sido a concepção da geografia como uma ciência em movimento e não como descrição da Terra” (Seemann, 2012:10).

O estudo dos movimentos esteve, portanto, na aurora do pensamento geográfico institucionalizado na Europa e também compõe o arsenal de fenômenos dos primeiros autores autointitulados geógrafos culturais. Carl Sauer, por exemplo, fundador da escola de Berkeley, foi especialmente preocupado com a difusão espacial das culturas destacando a dispersão dinâmica de espécies vegetais e animais para entender as diferentes "morfologias das paisagens" (Sauer, 1998 [1925]). Para além de um difusionismo clássico na disciplina, focado nos processos civilizatórios e na materialidade das paisagens, muitas outras abordagens foram desenvolvidas ao longo do último século para tratar do tema do movimento da cultura material e imaterial na geografia (Blaut, 1994). 
Passando pela metodologia de estudo da difusão espacial das inovações do geógrafo Torsten Hagerstrand [1953] (1967), até abordagens mais contemporâneas sobre a circulação e recepção de textos científicos (Keighren, 2010), a geografia humana apresenta uma miríade de abordagens focadas no movimento e na mobilidade de artefatos, ideias e imagens e, claro, de corpos.

Longe de qualquer proposição retrospectiva, nossa intenção na presente edição de número 46 da $\mathrm{E} \& \mathrm{C}$ é evidenciar como, a despeito de vasta pluralidade temática e metodológica para tratar do tema, o movimento segue com relevo no trabalho das geógrafas e geógrafos na contemporaneidade. Desta feita, o que une os artigos aqui publicados é justamente o tema da circulação de imagens, textos e ideias que possibilitou o estabelecimento de conexões entre espaços e tempos distintos. A imagem do fotógrafo Maurício Hora, que ilustra a capa de nossa edição, compõe a potente exposição "Morro da Favela à Providência de Canudos" que ocupou o Espaço Cultural do Banco Nacional de Desenvolvimento Econômico e Social entre os dias 24 de maio a 14 de julho do ano de 2017. A imagem de Maurício Hora não foi escolhida apenas por sua beleza, mas também porque expressa de modo intenso processos de circulação, de significação e ressignificação das paisagens que estão compondo também os textos da edição.

Há muitos movimentos na imagem de Maurício Hora. Podemos pensar na produção da imagem, que revela o movimento do próprio corpo do fotógrafo, que se desloca do Morro da Providência, na cidade do Rio de Janeiro, para o sertão baiano, para registrar as ruínas de Canudos emersas após uma grande seca ocorrida na região. A mobilidade do corpo do fotógrafo, equipado com artefatos tecnológicos específicos - sua câmera, lentes, tripés, rolos de filme - enseja a criação de um olhar original sobre as paisagens redescobertas de Canudos.

Após serem produzidas no campo, as imagens de Maurício Horta viajam, ainda dentro da câmera escura, de volta ao Rio de Janeiro, onde são finalmente reveladas e imediatamente colocadas em relação com outras imagens, no diálogo proposto por Maurício com imagens de seu local de pertencimento, o Morro da Providência. A circulação das imagens permite assim articular tempos e espaços longínquos, revelando e conectando histórias escondidas e emersas de diferentes contextos sociais, culturais e políticos. Após serem processadas, selecionadas e 
colocadas em relação com outras imagens, as fotografias do sertão são finalmente expostas para uma outra audiência, ganhando novas camadas de significado na exibição em um novo contexto. Durante o período de exibição, as fotografias, amplificadas e impressas com técnicas modernas, foram recepcionadas por um público variado que envolveu desde os trabalhadores que montaram a exposição, os visitantes do espaço cultural, professores e colegas do fotógrafo. As impressões e reflexões motivadas pelas imagens de Maurício Horta dão corpo aos dois primeiros textos que abrem essa edição.

No artigo “A Favela e o Sertão na Fotografia de Maurício Hora: a construção de uma narrativa de presença e legitimidade” a geógrafa e professora do Departamento de Geografia Humana da Universidade do Estado do Rio de Janeiro, Julia Santos Cossermelli de Andrade explora o percurso do fotógrafo e a importância de sua narrativa contra hegemônica na afirmação de sujeitos silenciados nas políticas do Estado e nas histórias oficiais. A autora nos conta sobre a atuação de Maurício Hora em 2013 quando registrou em suas lentes a luta dos moradores do Morro da Providência face às grandes intervenções urbanísticas no contexto do projeto urbano do Porto Maravilha. Ao escavar a materialidade da paisagem, novos vestígios aparecem e a conexão com outros tempos nos permite observar "verdadeiros documentos arqueológicos", como escreve a autora. Júlia relata ainda que, enquanto assistia a uma reportagem em um telejornal de notícias, Maurício teve conhecimento das ruínas de Canudos agora expostas no local onde antes ficava um açude no interior da Bahia, trazendo aos olhos uma história apagada na memória coletiva. Considerando as fotografias de Maurício Hora como documentos fundamentais para os estudos de geografia comprometidos com o pensamento decolonial, Júlia utiliza as imagens reunidas na exposição para oferecer uma reflexão crítica contundente sobre o silenciamento de narrativas nas paisagens contemporâneas.

Outro geógrafo também tocado pelas imagens de Mauricio Hora é Rafael Gonçalves de Almeida, professor do Instituto Federal de Educação Ciência e Tecnologia do Rio Grande do Norte. Rafael, cuja tese sobre a geografia histórica das favelas da cidade do Rio de Janeiro recebeu o prêmio de Melhor Tese de Geografia em 2017 pela Capes, foi convidado pela professora Julia Santos 
Cossermelli de Andrade para participar de um debate sobre a exposição de Maurício Hora no Centro Cultural do BNDES. Como conta em seu texto, Rafael percorre a exibição inicialmente como geógrafo histórico que relaciona as imagens ali expostas a uma série de referências e documentos históricos sobre as favelas da cidade. Seu artigo aqui publicado, intitulado "A Ressignificação do Mito de Origem da Favela pela Arte de Maurício Hora" tensiona a associação entre a guerra de Canudos e a gênese das favelas do Rio de Janeiro, discutindo o papel da obra de Euclides da Cunha e do "mito de origem da favela" na construção de um discurso exterior sobre a formação histórica dessas comunidades. Todavia sua sensibilidade o possibilitou ir um pouco mais além da reflexão crítica, o levando a compreender que "aquilo que via não reproduzia uma história já contada, mas reinterpretava e transformava o mito de origem da favela”. $\mathrm{O}$ autor percebe que o olhar de Maurício Hora não buscava, portanto, analisar acontecimentos do passado, e conclui que é por meio de um olhar antropofágico que o fotógrafo “devora a narrativa racista de Euclides da Cunha” para produzir uma outra narrativa, reivindicando a história de Canudos como parte de sua própria história.

A temática da mobilidade das imagens está também presente no artigo de Lara D’Assunção dos Santos, doutoranda do Programa de Pós-Graduação em Geografia da Universidade do Estado do Rio de Janeiro. No texto "Explorações Geográficas nas Coleções Fotográficas: o projeto Gênesis como sobrevivência da cultura da exploração" a autora tece uma série de reflexões sobre as explorações geográficas a partir da obra Gênesis do fotógrafo brasileiro Sebastião Salgado com o objetivo de elaborar um olhar crítico sobre as viagens de campo dos geógrafos, que buscaram mapear aquilo que era visto como exótico e diferente. Ao associar a obra do consagrado fotógrafo com a circulação de imagens produzidas por geógrafos, Lara evidencia como o projeto Gênesis pode ser lido como uma prática de sobrevivência da cultura de exploração, associado não só ao deslocamento para lugares longínquos como também a uma série de "práticas reprodutivas", que permitem movimentar imagens imutáveis dos espaços para novas audiências e contextos de recepção. No intuito de conceitualizar e instrumentalizar as suas reflexões sobre o papel da fotografia na circulação de imaginários geográficos, a autora lança mão da noção de móbiles imutáveis de Latour (2015 [1986]), evidenciando a importância das técnicas que permitem não ESPAÇO E CULTURA, UERJ, RJ, N. 46, P.03-10, JUL./DEZ. DE 2019 http://www.e-publicacoes.uerj.br/index.php/espacoecultura/ 
apenas capitar as imagens, mas também juntá-las e deslocá-las de acordo com interesses específicos.

Latour é um autor chave na concepção da circulação e do movimento na geografia contemporânea e acreditamos que a visão original sobre o autor apresentada no artigo "Bruno Latour e a Geografia: o território desde uma perspectiva não moderna”, assinado pelo historiador e geógrafo David Alejandro Ramírez Palacios em pesquisa Pós-doutoral (PPHIST/UFPA)., pode estimular novos diálogos entre a geografia e os escritos do antropólogo francês. David oferece uma excelente síntese das ideias de Latour e propõe um diálogo bastante original entre as abordagens e ferramentas cunhadas por Latour e os estudos geográficos sobre história territorial. Considerando que a geografia tem sido historicamente a ciência das relações entre entidades heterogêneas e interdependentes, o autor considera uma possibilidade de diálogo com influencias mútuas. Por um lado, o pensamento de Bruno Latour possui uma "mensagem libertadora para a geografia", pois a "teoria do ator-rede" oferece uma compreensão do social em termos de associações e não como uma dimensão, âmbito, camada ou fatia da realidade. Por outro, a tradição da geografia política e sua forma de compreensão do conceito de território também pode contribuir às teorias relacionais pós-representacionais. Ao apresentar o vocabulário não dicotômico e antiessencialista de Latour, David também explora a ideia de móbiles imutáveis, considerando como a reprodução e a circulação de imagens e textos constitui um elemento fundamental na formação de redes associativas e conexões entre tempos e espaços distintos.

A circulação de ideias sobre espaços longínquos, que são articulados e pensados a partir de uma posição de exterioridade, está presente no quinto artigo desta edição da E\&C. No texto "Marx, o Mouro e o Oriente" de Breno Viotto Pedrosa, professor do Departamento de Geografia da Universidade Federal do Rio Grande do Sul, são apontadas as fontes de reflexão de Karl Marx sobre o Oriente, no intuito de contextualizar as suas influências na concepção de um modo de produção asiático. Lançando um olhar cuidadoso sobre os escritos de Marx e suas fontes, Breno identifica diferentes períodos na sua escrita sobre o Oriente, concluindo que ao longo da sua trajetória há um abandono de certos 
pontos de vistas hegelianos e a incorporação de perspectivas advindas dos estudos culturais e históricos de sua época. É interessante observar como a circulação dos corpos e o acesso a fontes de informação sobre diferentes partes do mundo volta a ser um tema importante aqui. Como evidencia Breno, antes da chegada de Marx à Inglaterra em 1850, os escritos do autor sobre o Oriente se baseavam em grande parte nas ideias de Hegel e Montesquieu. No entanto, ao se deslocar no espaço e estabelecer um novo local de moradia em Londres, "tudo muda, pois ele desfruta de uma vasta fonte de pesquisa sobre o continente”. Nesse momento Marx tem contato com relatos de viagem e relatórios dos administradores coloniais ingleses, passando a escrever mais constantemente sobre a inserção do capitalismo na Índia e o problema da agricultura no oriente. Como defende Breno, o contato com novos documentos "complexifica a sua visão sobre a China, a Índia e outras regiões do globo" o que faz com que a ideia do "o ponto cego" de Marx sobre o oriente se sustente parcamente tendo em conta o contexto da época e o desenvolvimento do pensamento marxiano.

Para finalizar nossa edição sobre a circulação de ideias e imagens, voltamos a Friederich Ratzel e orgulhosamente apresentamos a tradução para o português do tex to "Land und Landschaft in der nordamerikanischen" publicado em 1902, no qual o autor disserta sobre os Estados Unidos dando grande ênfase ao tema do movimento. A tradução foi realizada por Jörn Seemann, professor da Ball State University, nos Estados Unidos e revista por Breno Viotto Pedrosa, já apresentado anteriormente. Antecede à tradução, o artigo "Friedrich Ratzel e a Alma do Povo Americano" no qual Jörn e Breno introduzem o texto traduzido evidenciando que "uma das fascinações (ou até obsessões) principais de Ratzel foi a difusão dos seres humanos na superfície terrestre”. Os autores chamam nossa atenção para o fato de que os movimentos e migrações seriam, para Ratzel, "a problemática-chave de articulação entre geografia, história e antropologia”. Iniciando pelo estudo do movimento dos povos, Ratzel teria expandido suas ideias para a "difusão de objetos e ideias no tempo e no espaço", complexificando sua hipótese básica de que a cultura surge a partir do laço entre um povo e seu solo e que ela se move no espaço, se difundindo pelas migrações, trocas comerciais e pelos aprendizados das técnicas. 
Como bem evidenciam Jörn e Breno, essas perspectivas de Ratzel influenciaram consideravelmente a geografia cultural, pois geógrafos como Carl Sauer se inspiraram nas ideias do geógrafo alemão ao estudar a distribuição e a difusão de elementos culturais. Nada mais proveitoso para fechar essa revista sobre circulação de imagens e ideias do que oferecer ao público brasileiro as palavras do próprio Friedrich Ratzel, no texto "País e Paisagem na Alma do Povo Norte-Americano" que disserta sobre os processos de migração, povoamento e apropriação das terras da América do Norte. Longe de apresentar uma perspectiva estática e essencialista para tratar da "alma do povo", Ratzel explora as relações entre as culturas migrantes e as condições ambientais, enfatizando os laços entre a estrutura política de uma país e suas paisagens naturais.

Muito embora Jörn e Breno sejam cuidadosos e nos advirtam que as traduções muitas vezes são traições, pois existe uma dificuldade inerente na tradução de um tex to em escrito em Alemão no final do século XIX, entendemos que por meio de traduções e adaptações que as ideias circulam. Assim como as imagens, não é possível um controle sobre a recepção das ideias que estarão sempre abertas a novas interpretações quando se deparam com uma nova audiência e um novo contexto de recepção. Considerando a própria revista $\mathrm{E} \& \mathrm{C}$ como um espaço de produção, circulação e recepção de ideias e imagens sobre as abordagens culturais na geografia, temos muito orgulho em compartilhar o número 46 da nossa revista com os leitores.

Desejamos uma ótima leitura a todas e todos!

Mariana Lamego

André Reyes Novaes

\section{REFERÊNCIAS BIBLIOGRÁFICAS}

BLAUT, James. Diffusionism: a uniformitarian critique. In FOOTE, K. et alli (Org.) Re-reading Cultural Geography. Austin: University of Texas Press, 1994, p.173-190.

HÄGERSTRAND, Torsten. [1953] Innovation difusion as a spatial process. Chicago: University of Chicago Press, 1967. 
KEIGHREN, Innes M. Bringing Geography to Book: Ellen Semple and the reception of geographical knowledge. London: I.B.Tauris, 2010

LATOUR, Bruno. [1986] Cognição e visualização: Pensando com olhos e mãos. Terra Brasilis (Nova Série). Revista da Rede Brasileira de História da Geografia e Geografia Histórica, n. 4, 13 fev. 2015. Tradução David Palacios. Disponível em: <http://terrabrasilis.revues.org/1308>.

SEEMANN, Jörn. Friedrich Ratzel entre Tradições e Traduções. Terra Brasilis (Nova Série). Revista da Rede Brasileira de História da Geografia e Geografia Histórica, n. 1, 2012. Disponível em: < http://journals.openedition.org/terrabrasilis/180>

SAUER, Carl O. [1925] A morfologia da paisagem. In ROSENDAHL, Z. e CORREA, R. L. Paisagem, Tempo e Cultura. Rio de Janeiro: EdUERJ, 1998. 